\title{
Physical activity, sedentary behavior, and the risk of colon and rectal cancer in the NIH-AARP Diet and Health Study
}

\author{
Regan A. Howard ${ }^{1}$, D. Michal Freedman ${ }^{1}$, Yikyung Park ${ }^{2}$, Albert Hollenbeck ${ }^{3}$, Arthur \\ Schatzkin ${ }^{2}$, and Michael F. Leitzmann ${ }^{2}$ \\ 1 Division of Cancer Epidemiology and Genetics, Radiation Epidemiology Branch, National Cancer Institute, \\ Bethesda, MD \\ 2 Division of Cancer Epidemiology and Genetics, Nutritional Epidemiology Branch, National Cancer \\ Institute, Bethesda, MD \\ 3 AARP, Washington, DC
}

\section{Abstract}

Objective-In order to prospectively investigate physical activity at varying intensities and sedentary behavior in relation to colorectal cancer.

Methods-We considered 488,720 participants of the NIH-AARP Diet and Health Study who were aged 50-71 years at baseline in 1995-1996. Through 31 December, 2003, we identified 3,240 and 1,482 colorectal cancers among men and women, respectively. We estimated multivariable relative risks (RR) and 95\% confidence intervals (CI) of colorectal cancer using Cox regression.

Results-Engaging in exercise/sports five or more times per week compared to never or rarely exercising was associated with a reduced risk of colon cancer among men $(p=0.001 ; \mathrm{RR}=0.79,95 \%$ $\mathrm{CI}=0.68-0.91)$ and a suggestive decrease in risk among women $(p=0.376 ; \mathrm{RR}=0.85,95 \% \mathrm{CI}=0.70$ 1.04). Engaging in exercise/sports was also associated with a decreased risk of rectal cancer in men ( $P=0.074$; RR comparing extreme categories $=0.76,95 \% \mathrm{CI}=0.61-0.94)$. In men, we observed inverse relations of both low intensity $(p=0.017 ; \mathrm{RR}=0.81,95 \% \mathrm{CI}=0.65-1.00 \mathrm{for} \geq 7 \mathrm{~h} /$ week) and moderate to vigorous intensity activity $(p=0.037 ; \mathrm{RR}=0.82,95 \% \mathrm{CI}=0.67-0.99 \mathrm{for}=7 \mathrm{~h} /$ week) to colon cancer risk. In contrast, sedentary behavior (time spent watching television/videos) was positively associated with colon cancer $(p<0.001 ; \mathrm{RR}=1.61,95 \% \mathrm{CI}=1.14-2.27 \mathrm{for} \geq 9 \mathrm{~h} /$ day $)$ among men. Similar, but less pronounced relations were observed in women.

Conclusion-Engaging in physical activity of any intensity is associated with reductions in colon and rectal cancer risk. Conversely, time spent sedentary is associated with increased colon cancer risk.

\section{Keywords}

Colon cancer; Rectal cancer; Physical activity; Cohort studies

\section{INTRODUCTION}

Colon cancer is the third most common cancer among both men and women and it currently accounts for approximately $10 \%$ of all cancer deaths in the United States [1]. Increased physical activity has been consistently associated with decreased risk of colon cancer [2-5], with both

Correspondence to: Regan Howard, National Cancer Institute, NIH, DHHS, Executive Plaza South, Suite 7091, Bethesda, MD 20892, Phone: 301-594-7905, Fax: 301-402-0207; Email: reganho@mail.nih.gov. 
prospective [6-18] and case-control studies [19-27] reporting risk reductions of about 40\% with high versus low levels of physical activity, particularly among men. Studies of physical activity and colon cancer among women have been much less consistent, with no statistically significantly association reported in most $[6,8,10,11,15,16,28-34]$, but not all studies [12,13, $16,35]$. Further, site-specific associations between physical activity and colon cancer have been largely inconclusive, with relatively few cohort studies reporting results by anatomical subsite $[12,13,16,18,33,36,37]$. It is also unclear how physical activity performed during different age periods may affect colon cancer risk since many studies have been unable to detect associations with past physical activity $[9,14,16,18,34,35,38]$. In order to address these issues, in a large prospective study we examined in detail the relations of physical activity at varying intensities and sedentary behavior to colon and rectal cancer according to gender, colorectal sub-site, and age period of activity.

\section{MATERIALS AND METHODS}

\section{The NIH-AARP Diet and Health Study}

The NIH-AARP Diet and Health Study was established in 1995-1996 when 567,169 men and women responded to a mailed baseline questionnaire that requested information on diet, family history of cancer, physical activity, anthropometry, and other lifestyle factors [39].

Respondents were members of AARP between the ages of 50-71 years old at baseline and residing in one of eight study areas (California, Florida, Pennsylvania, New Jersey, North Carolina, Louisiana, and metropolitan Atlanta and Detroit). In 1996-1997, a second questionnaire was sent to respondents who did not have self-reported prostate, breast, or colorectal cancer at baseline to collect more detailed information on physical activity and sedentary behavior. A total of 334,908 respondents completed the second questionnaire. The NIH-AARP Diet and Health Study was approved by the Special Studies Institutional Review Board of the U.S. National Cancer Institute and all participants provided written informed consent.

\section{Study population}

Among baseline questionnaire respondents, we excluded 179 duplicate questionnaires, 15,760 individuals whose questionnaires were completed by proxies for the intended respondents, 582 persons who died or moved out of the study area before study entry, and 6 people who withdrew from the study. We also excluded 51,193 persons with a previous cancer diagnosis, 997 persons reporting end-stage renal disease, 5,711 subjects with missing information on physical activity, and 4,021 persons who were statistical outliers on reported energy intake. After exclusions, a total of 488,720 subjects (292,069 men and 196,651 women) remained for analysis of the baseline questionnaire. The same exclusion criteria were applied to persons responding to the second questionnaire resulting in 300,673 (175,600 men and 125,073 women) subjects available for the analyses regarding that questionnaire.

\section{Cohort maintenance}

Participants of the NIH-AARP cohort are followed annually for change of address by matching the cohort database to that of the National Change of Address maintained by the U.S. Postal Service (USPS). Information on address changes is also obtained through receipt of USPS processing of undeliverable mail, from other address change update services, and directly from participants who report address changes in response to study mailings such as questionnaires, newsletters, sample kits, etc. Vital status is ascertained by annual linkage of the cohort to the Social Security Administration Death Master File (SSA DMF) on deaths in the U.S., followup searches of the National Death Index for subjects that match to the SSA DMF, cancer registry linkage, questionnaire responses, and responses to other mailings. 


\section{Assessment of physical activity}

The baseline questionnaire asked participants to provide information about the number of times per week during the last 12 months they engaged in periods of physical activity or sports that lasted at least $20 \mathrm{~min}$ and caused increases in breathing or heart rate, or caused them to work up a sweat (i.e., current exercise/sports). There were six possible response options: never; rarely; $1-3$ times per month; $1-2$ times per week; $3-4$ times per week; and 5 or more times per week. Subjects were also asked to indicate which of the following categories best described their routine throughout the day at home or work (i.e., daily routine activity): sitting, sitting and walking, standing or walking but not lifting or carrying things, carrying light loads or climbing stairs, and carrying heavy loads or doing heavy work.

The second questionnaire inquired about physical activity during different ages (15-18 years, 19-29 years, 35-39 years, and in the past 10 years). For each age period, subjects were asked to report the average number of hours per week spent at low intensity activities (e.g., slow walking, bowling, light calisthenics, light gardening, light housework) and at moderate to vigorous activities (e.g., brisk walking, jogging, aerobics, heavy gardening, heavy housework). Response options for each of those items were as follows: never; rarely; weekly, but less than $1 \mathrm{~h}$ per week; 1-3 h per week; 4-7 h per week; and more than $7 \mathrm{~h}$ per week. A median value for the number of hours per week of physical activity was assigned and multiplied by the estimated metabolic equivalent task (MET) value specific to that intensity level. One MET is defined as the energy expended while sitting quietly and is approximately equal to $3.5 \mathrm{ml}$ of oxygen uptake per kilogram of body weight per minute for a 70-kg adult [40]. The estimated MET values used for the two intensity categories (low intensity activity and moderate to vigorous activity) were created by averaging individual MET values from all specific activities included in that category. A total physical activity score was created by summing the METhours per week of low intensity activity and moderate to vigorous activity reported during each age period. A lifetime physical activity score was created by averaging the total physical activity scores calculated for each age period.

The second questionnaire also requested information on sedentary behavior by asking about the average number of hours per day currently spent watching television or videos, and the average number of hours per day spent sitting. The response options for those items were as follows: none; less than $1 \mathrm{~h} ; 1-2 \mathrm{~h} ; 3-4 \mathrm{~h} ; 5-6 \mathrm{~h} ; 7-8 \mathrm{~h}$; and 9 or more hours. The reliability and validity of questionnaires to assess physical activity similar to the ones used in this study have been evaluated in similar U.S. cohorts and found to provide useful information [41].

\section{Identification of cases}

Histologically confirmed incident colon and rectal cancer cases through 31 December, 2003, were ascertained through probabilistic linkage to the eight state cancer registries serving our cohort and three additional states (AZ, NV, and TX), all of which met the certification requirements defined by the North American Association of Central Cancer Registries, which are estimated to have $90 \%$ case ascertainment within 24 months [42]. For matching purposes, we have virtually complete data on first and last name, address history, gender, and date of birth. All suspected matches underwent a process that rejects those with insufficient degree of similarity to confirm a true match (approximately 4\%); uncertain matches underwent final manual review. We conducted a validation study of cancer endpoint ascertainment by linking a subset of our cohort $(n=12,000)$ to the cancer registries and comparing the data to self-reports and subsequent medical record confirmation of incident cancer in this sub-cohort. We found that approximately $90 \%$ of all incident cancers were accurately identified using the registries included in this cohort as the gold standard [42]. 
We used the International Classification of Diseases for Oncology, 3rd edition, to classify incident cases of colon cancer (C180-189) and rectosigmoid and rectal cancer (C199 and C209). Colon cancers were further subdivided into cancers of the proximal colon (C180-184) and distal colon (C185-187). Participants diagnosed simultaneously with a colon and rectal cancer were included in both colon and rectal cancer analyses. Deaths due to colorectal cancer were, in addition, identified through linkage to the National Death Index Plus. We estimate that ascertainment of deaths in our cohort is more than $93 \%$ complete [43].

\section{Statistical analysis}

We used Cox proportional hazards regression to estimate relative risks (RR) and 95\% confidence intervals (CI) of colon or rectal cancer using age as the underlying time metric [44]. We tested and verified that the proportional hazards assumption was not violated for our main exposures and the covariates by including appropriate cross product terms with age and testing that all coefficients equaled zero. Analyses were stratified by gender and conducted separately for colon and rectal cancers because of an a priori hypothesis that the association between physical activity and colorectal cancer may vary by tumor sub-site and gender. Persontime began from the age at which a questionnaire was returned and ended at the age of diagnosis of colon or rectal cancer, death, move out of cancer registry catchment area, or the end of the study follow-up (31 December, 2003), whichever occurred first. Since information on sedentary behavior and more detailed information on physical activity was first reported in the second questionnaire, follow-up in analyses involving these more extensive assessments began in 1996-1997. Total person-time may vary between analyses due to exclusion of subjects with missing physical activity data.

Three models were used to evaluate the relationship between physical activity and colon or rectal cancer. The first model adjusted for age only. The second model, in addition, included smoking (never, quit $\leq 20$ cigarettes/day, quit $20+$ cigarettes/day, currently smoking $\leq 20$ cigarettes/day, currently smoking 20+ cigarettes/day, unknown), alcohol consumption (grams/ day: $0,<5,5-15,15-30,30-50,50+)$, education ( $<12$ years, high school graduate, post-high school, any college and post-graduate, unknown), race (white, black, other, unknown), family history of colon cancer (yes, no, unknown), total energy, and energy-adjusted intakes (quintiles) of red meat, calcium, whole grains, fruits, and vegetables. We also adjusted for menopausal hormone therapy in women (never, former user, current user, unknown). The third model, in addition, adjusted for body mass index (BMI) $\left(\mathrm{kg} / \mathrm{m}^{2}\right.$ : $<20.0,20.0-22.4,22.5-24.9$, 25.0-27.4, 27.5-29.9, 30.0-31.9, 32.0-33.9, 34.0+, unknown). Since BMI is potentially in the causal pathway between physical activity and colon cancer, we evaluated risks adjusted for BMI separately. We created missing indicator variables to reflect missing data for each covariate. Variables representing activity intensity and sedentary behavior were mutually adjusted. Additional variables evaluated for potential confounding included screening for colorectal cancer, aspirin/NSAID use, oral contraceptive use, marital status, multivitamin use, and energy-adjusted total intakes of total fat, dietary fiber, vitamin C, vitamin D, vitamin E, folate, and iron. The results were similar to those from the parsimonious model and were not included in final models.

Linear trend tests were conducted by modeling the median value of each category as a single continuous variable. We examined effect modification by including a cross-product interaction term between the physical activity variable and the covariate of interest along with the main effects terms in the appropriate multivariable model. The coefficient of the interaction term was assessed using a Wald test. Effect modification was evaluated both using the full cohort and separately among men and women. Statistical analyses were conducted using the SAS Statistical Software, version 9.1. All $P$ values were two-sided and considered statistically significant at an a level of $<0.05$. 


\section{RESULTS}

The 488,720 participants contributed 3,355,603 person-years of follow-up during a mean follow-up of 6.9 years. Among men, a total of 2,298 colon and 942 rectal cancers were identified and among women 1,112 colon and 370 rectal cancers were identified. Baseline participant characteristics by frequency of current exercise/sports activity are shown in Table 1. Men and women who were more physically active tended to have a lower BMI, they were less likely to smoke, and they reported consuming less red meat than those who were less physically active. In addition, physically active participants had a higher level of education and they consumed more fruits, vegetables, calcium, and folate than less physically active subjects. Women with greater physical activity were more likely to be currently taking menopausal hormone therapy than their less active counterparts.

Among men and women, participants who engaged in exercise/sports 5 or more times per week had an $18 \%$ reduced risk of colon cancer $(\mathrm{RR}=0.82 ; 95 \% \mathrm{CI}=0.73-0.92)$ compared to those who reported never or rarely exercising. In addition, colon cancer risk was inversely related to increasing level of daily routine activity ( $p=0.003$ ), with the lowest risk observed for participants reporting climbing stairs or lifting light loads as part of their daily routine $(\mathrm{RR}=0.73 ; 95 \% \mathrm{CI}=0.63-0.85)$. We next stratified the cohort according to gender in order to examine more closely the effect of physical activity in men and women, although the formal test for interaction was not statistically significant $(p=0.322)$. In men, increasing frequency of current exercise/sports participation was associated with a graded, statistically significant decrease in colon cancer risk in both age and multivariable-adjusted models (Table 2). Men who reported engaging in exercise/sports 5 or more times per week had a $21 \%$ lower risk of colon cancer than men who reported never or rarely exercising ( $\mathrm{RR}=0.79 ; 95 \% \mathrm{CI}=0.68-0.91)$. Additional adjustment for BMI had limited impact, thus subsequent results in the text are presented for multivariable-adjusted models without BMI unless otherwise stated. Among women, current exercise/sports was inversely associated with colon cancer in age-adjusted analyses, but showed no statistically significant trend with colon cancer after adjustment for covariates. However, the multivariable-adjusted relative risks were decreased for women who reported exercising 1-3 times per month or 3-4 times per week compared to women who never or rarely exercised.

We next investigated daily routine activity in relation to colon cancer risk. As compared with men who reported mostly sitting throughout the day, men who reported engaging in a combination of sitting and walking, walking and standing, and climbing stairs, or hills, or lifting, or carrying light loads had a statistically significant decreased risk of colon cancer (Table 2). Risk did not further decrease among men in the top category of daily routine activity which comprised heavy work or carrying heavy loads, although case numbers were small in that category ( $n=82$ cases). Similarly, among women all but the highest level of daily routine activity were statistically significantly associated with reduced risk of colon cancer in ageadjusted analyses. Associations inwomen became statistically nonsignificant in multivariableadjusted models.

We next evaluated the relation of physical activity to colorectal cancer according to anatomic sub-site (Table 3). Among men, inverse associations with current exercise/sports activity were seen for proximal and distal colon cancers and for rectal cancers. Sub-site results showed some similarities among women, with statistically significant age-adjusted associations for both proximal and distal colon cancers and a significant test for trend for distal colon cancers and rectal cancers, all of which, however, became nonsignificant after multivariable adjustment. Among men, inverse associations were found between daily routine activity and proximal $(p=0.028)$ and distal colon cancers $(p=0.008)$ but not rectal cancers $(p=0.163)$. Among women, a suggestive inverse relation was noted between increasing level of daily routine activity and 
proximal cancers. Associations with distal colon cancers and rectal cancers showed no consistent patterns among women. For both men and women, risk estimates for rectal cancer did not differ appreciably from cancers of the rectosigmoid junction (data not shown).

We assessed the time spent at low intensity activity, moderate to vigorous intensity activity, and sedentary behavior in relation to risk of colon cancer (Table 4). As compared with men never or rarely engaging in low intensity activity (such as walking), men reporting more than $7 \mathrm{~h}$ per week of low intensity activity had a RR of colon cancer of 0.81 (95\% CI=0.65-1.00), even after adjustment for moderate to vigorous intensity activity. Similarly, our assessment of moderate to vigorous activity demonstrated an inverse dose-response relationship for colon cancer in men $(p=0.037)$, independent of time spent in low intensity activity, although the relation appeared to level off in the highest category of moderate to vigorous activity. When we examined the combination of low intensity activity and moderate to vigorous activity (i.e., total activity) in men, the RR comparing extreme quintiles was 0.76 (95\% CI=0.63-0.90). With regards to sedentary behavior in men, 9 or more hours versus less than $3 \mathrm{~h}$ per day of watching television or videos was associated with a RR of colon cancer of 1.61 (95\% CI=1.14-2.27). Overall time spent sitting was also suggestively associated with colon cancer in men $(p=0.050)$. Among women, no statistically significant relations with colon cancer were observed for low intensity activity, moderate to vigorous activity, and the combination of low intensity activity and moderate to vigorous activity, or time spent sitting. However, increasing time spent watching television was statistically significantly associated with increased colon cancer risk in age-adjusted models among women. Multivariable risks for sedentary behavior among men and women were similar with or without adjustment for physical activity.

We investigated colon cancer risk according to total physical activity during different age periods of life. Physical activity variables for different age periods were positively correlated with one another; the correlation coefficients ranged from 0.30 to 0.91 and values decreased with increasing time between age periods. Among men, total physical activity at ages 15-18 and ages 19-29 years was not associated with colon cancer, whereas a decrease in colon cancer risk was observed with increasing levels of total physical activity at ages 35-39 years and increasing levels of total lifetime physical activity (Table 5). The RR comparing extreme quintiles of total lifetime activity was $0.82(95 \% \mathrm{CI}=0.69-0.98)$. In contrast, among women no relations of total physical activity at ages $15-18$, ages $19-29$, ages $35-39$, or total lifetime physical activity to colon cancer were observed. In further analyses of past activity, we in addition adjusted for total current activity. No appreciable differences in risk estimates emerged, indicating that observed relations with past activity were independent of current activity (data not shown).

The associations of physical activity and sedentary behavior to colon cancer risk were not modified by age, body mass, education, race, family history of colon cancer, history of colorectal cancer screening, alcohol consumption, smoking status, aspirin/NSAID use, or menopausal hormone therapy (women only).

\section{DISCUSSION}

In this large prospective investigation, we observed inverse associations between various indices of physical activity and risk of colon cancer. In men, both low intensity activities such as walking and more vigorous forms of activity appeared to protect against colon cancer, and risk reduction associated with physical activity was apparent for proximal, distal, and rectal cancers. In addition, reported recent physical activity among men was associated with greater benefit than activity at earlier periods in life, and sedentary behavior was independently associated with increased risk. In women, physical activity was less strongly associated with 
colon and rectal cancers. However, risk estimates were generally in the same direction as observed in men.

Our finding of an inverse association between physical activity and colon and rectal cancer risk is largely consistent with evidence from previous studies [3-5]. Findings from available epidemiologic studies of women have been less conclusive, with results from several prospective studies observing no association $[6,8,15,32]$ and others reporting statistically nonsignificant risk reductions [33,34]. Few studies found a statistically significant inverse association between physical activity and colorectal cancer in women [13,16,35]. Although we cannot entirely dismiss the possibility that men and women have biologically distinct responses to exercise, we must also consider the potential for misclassification of physical activity due to the difficulties inherent in measuring physical activity in women. Data derived from physical activity diaries $[45,46]$ suggest that women spend between 30 minutes to 6 hours per day doing household chores and family care activities with time spent in occupational activities ranging from 4 to $16 \mathrm{~h}$ per day [47]. Thus, the variable nature of women's lives makes it challenging to accurately assess their physical activity. This increases the difficulty in detecting a modest association, such as between physical activity and colon cancer, for women.

In this study, the inverse dose-response relationship between current exercise/sports activity and colon cancer risk did not appear to vary appreciably between proximal and distal colon cancers for men or women. Few cohort studies of physical activity and colon cancer have conducted analyses stratified by tumor sub-site [6,12,13,16-18,32-34,36,37,48,49], with those that did yielding conflicting results. Some studies reported stronger inverse findings for the proximal colon $[12,16,17,33,48]$, while others observed stronger inverse associations for distal colon sites $[6,13,18,36,37]$. Observed differences may be due to varying etiologies between tumors of the proximal and distal colon [50].

We observed a decreased risk of rectal cancer among vigorously active men in our study, which is in agreement with several recent investigations [16,18,51,52]. In the Cancer Prevention Study II Cohort, a 30\% lower risk of rectal cancer was observed among both men and women who reported any versus no physical activity in the year preceding study enrollment [16]. Results of the Fukuoka Colorectal Cancer Study showed that job-related as well as total and moderate leisure-time physical activity were associated with a significant reduction of rectal cancer risk in men only [51]. In contrast, several cohort studies [12,17,33] have failed to detect an association between physical activity and rectal cancer.

The intensity of physical activity required to reduce colon cancer risk is an important public health issue. We found that both low intensity and moderate to vigorous intensity activity was independently associated with decreased colon cancer risk to similar magnitudes in men. Most previous studies reporting on physical activity intensity suggest that vigorous exercise is more strongly associated with colon cancer risk reduction than light or moderate activity [3].

However, in the California Teachers Study moderate physical activity was associated with a stronger colon cancer risk reduction than strenuous physical activity among women [34].

Most previous studies examining the association between sedentary behavior and physical activity have done so within the context of occupational activity [21,31,37,53]. Le Marchand et al. [53] presented evidence that the number of years spent in sedentary or light work only was directly associated with cancer of the proximal colon in both men and women. A casecontrol study conducted by Whittemore et al. [21] observed that the risk for colon and rectal cancer increased with increasing time spent sitting and for those reporting an overall sedentary lifestyle. To our knowledge, ours is the first large cohort study to document risk of colon cancer associated specifically with time spent in sedentary activities outside of an occupational setting. Our results indicate that sedentary behavior, in particular television watching among men, is 
independently associated with an increased risk of colon cancer, even after adjustment for time spent participating in physical activity and body mass index.

Few studies have investigated the association between lifetime physical activity and colon cancer. Most previous studies report on adult physical activity often recording activity occurring close in time to study baseline. Results of our study suggest that physical activity associations with colon cancer are stronger for activity reported at recent ages than activity at earlier times. This finding is consistent with most previous reports of lifetime activity $[9,14$, $16,18,38]$, although data should be interpreted cautiously since subjects may less accurately recall past activities, particularly past light activities [54].

Our study has several strengths, including its prospective design, large cohort size with many incident cancer cases, and wide variety of physical activity indices including those for sedentary behavior. We also had extensive information on many known or suspected colon cancer risk factors, which reduced potential confounding and allowed us to evaluate effect modification. Potential limitations of this study result from the use of self-reported as opposed to objective assessments of physical activity. However, studies comparing physical activity measures similar to ours with validation instruments indicate that our instrument provides useful information [41]. Moreover, our activity data were associated with body mass and total energy intake in the hypothesized directions, further suggesting construct validity of our physical activity assessment.

Hypothesized mechanisms through which physical activity may protect against colon cancer include reduced gastrointestinal transit time, avoidance of positive energy balance, decreased levels of insulin and insulin-like growth factors (IGFs), and enhanced immune function [3]. It remains unclear what role these mechanisms may have for regulating rectal cancer risk. Previous research suggests that the risk factors for colon and rectal cancer sites may differ [55].

Our study is among the largest investigations to date to examine physical activity in relation to colorectal cancer and it confirms previously documented inverse associations between physical activity and colorectal cancer risk. Our findings add support to the limited available evidence that recent physical activity is more strongly associated with risk reduction than distant past activity, and that increased vigorous activity may protect against rectal cancer, particularly in men. Further, our results suggest that engaging in physical activity of any intensity is associated with reductions in colon and rectal cancer risk. In addition, we present novel findings, requiring replication, that recreational time spent sedentary, such as television or video watching, is associated with increased risk of colon cancer, independent of physical activity and body mass.

\section{References}

1. American Cancer Society. Cancer facts and figures 2007. American Cancer Society; Atlanta, GA: 2007.

2. Friedenreich CM. Physical activity and cancer prevention: from observational to intervention research. Cancer Epidemiol Biomarkers Prev 2001;10:287-301. [PubMed: 11319168]

3. Slattery ML. Physical activity and colorectal cancer. Sports Med 2004;34:239-252. [PubMed: 15049716]

4. Samad AKA, Taylor RS, Marshall T, Chapman MAS. A meta-analysis of the association of physical activity with reduced risk of colorectal cancer. Colorectal Dis 2005;7:204-213. [PubMed: 15859955]

5. Harriss DJ, Cable NT, George K, Reilly T, Renehan AG, Haboubi N. Physical activity before and after diagnosis of colorectal cancer: disease risk, clinical outcomes, response pathways and biomarkers. Sports Med 2007;37:947-960. [PubMed: 17953466] 
6. Wu AH, Paganini-Hill A, Ross RK, Henderson BE. Alcohol, physical activity and other risk factors for colorectal cancer: a prospective study. Br J Cancer 1987;55:687-694. [PubMed: 3620314]

7. Albanes D, Blair A, Taylor PR. Physical activity and risk of cancer in the NHANES I population. Am J Public Health 1989;79:744-750. [PubMed: 2729471]

8. Ballard-Barbash R, Schatzkin A, Albanes D, et al. Physical activity and risk of large bowel cancer in the Framingham study. Cancer Res 1990;50:3610-3613. [PubMed: 2340509]

9. Lee IM, Paffenbarger RS, Hsieh CC. Physical activity and risk of developing colorectal cancer among college alumni. J Natl Cancer Inst 1991;83:1324-1329. [PubMed: 1886158]

10. Thun MJ, Calle EE, Namboodiri MM, et al. Risk factors for fatal colon cancer in a large prospective study. J Natl Cancer Inst 1992;84:1491-1500. [PubMed: 1433333]

11. Bostick RM, Potter JD, Kushi LH, et al. Sugar, meat, and fat intake, and non-dietary risk factors for colon cancer incidence in Iowa women (United States). Cancer Causes Control 1994;5:38-52. [PubMed: 8123778]

12. Thune I, Lund E. Physical activity and risk of colorectal cancer in men and women. Br J Cancer 1996;73:1134-1140. [PubMed: 8624277]

13. Martinez ME, Giovannucci E, Spiegelman D, Hunter DJ, Willett WC, Colditz GA. Leisure-time physical activity, body size, and colon cancer in women. J Natl Cancer Inst 1997;89:948-955. [PubMed: 9214674]

14. Lee IM, Manson JE, Ajani U, Paffenbarger RS, Hennekens CH, Buring JE. Physical activity and risk of colon cancer: the Physician's Health Study (United States). Cancer Causes Control 1997;8:568574. [PubMed: 9242472]

15. Nilsen TI, Vatten LJ. Prospective study of colorectal cancer risk and physical activity, diabetes, blood glucose and BMI: exploring the hyperinsulinaemia hypothesis. Br J Cancer 2001;84:417-422. [PubMed: 11161410]

16. Chao A, Connell CJ, Jacobs EJ, et al. Amount, type, and timing of recreational physical activity in relation to colon and rectal cancer in older adults: the Cancer Prevention Study II Nutrition Cohort. Cancer Epidemiol Biomarkers Prev 2004;3:2187-2195. [PubMed: 15598779]

17. Friedenreich C, Norat T, Steindorf K, et al. Physical activity and risk of colon and rectal cancers: The European prospective investigation into cancer and nutrition. Cancer Epidemiol Biomarkers Prev 2006;15:2398-2407. [PubMed: 17164362]

18. Larsson SC, Rutegard J, Bergkvist L, Wolk A. Physical activity, obesity, and risk of colon and rectal cancer in a cohort of Swedish men. Eur J Cancer 2006;42:2590-2597. [PubMed: 16914307]

19. Slattery ML, Schumacher MC, Smith KR, West DW, Abd-Elghany N. Physical activity, diet, and risk of colon cancer in Utah. Am J Epidemiol 1988;128:989-999. [PubMed: 3189298]

20. Gerhardsson de Verdier M, Steineck G, Hagman U, Rieger A, Norell SE. Physical activity and colon cancer: a case-referent study in Stockholm. Int J Cancer 1990;46:985-989. [PubMed: 2249904]

21. Whittemore AS, Wu-Williams AH, Lee M, et al. Diet, physical activity, and colorectal cancer among Chinese in North America and China. J Natl Cancer Inst 1990;82:915-926. [PubMed: 2342126]

22. Longnecker MP, Gerhardsson de Verdier M, Frumkin H, Carpenter C. A case-control study of physical activity in relation to risk of cancer of the right colon and rectum in men. Int J Epidemiol 1995;24:42-50. [PubMed: 7797355]

23. White E, Jacobs EJ, Daling JR. Physical activity in relation to colon cancer in middle-aged men and women. Am J Epidemiol 1996;144:42-50. [PubMed: 8659484]

24. Levi F, Pasche C, Lucchini F, Tavani A, La Vecchia C. Occupational and leisure-time physical activity and the risk of colorectal cancer. Eur J Cancer Prev 1999;8:487-493. [PubMed: 10643937]

25. Tavani A, Braga C, La Vecchia C, et al. Physical activity and risk of cancers of the colon and rectum: an Italian case-control study. Br J Cancer 1999;79:1912-1916. [PubMed: 10206313]

26. Steindorf K, Tobiasz-Adamczyk B, Popiela T, et al. Combined risk assessment of physical activity and dietary habits on the development of colorectal cancer. A hospital-based case-control study in Poland. Eur J Cancer Prev 2000;9:309-316. [PubMed: 11075883]

27. Steindorf K, Jedrychowski W, Schmidt M, et al. Case-control study of lifetime occupational and recreational physical activity and risks of colon and rectal cancer. Eur J Cancer Prev 2005;14:363371. [PubMed: 16030427] 
28. Pukkala E, Poskiparta M, Apter D, Vihko V. Life-long physical activity and cancer risk among Finnish female teachers. Eur J Cancer Prev 1993;2:369-376. [PubMed: 8401170]

29. Steenland K, Nowlin S, Palu S. Cancer incidence in the National Health and Nutrition Survey I. Follow-up data: diabetes, cholesterol, pulse and physical activity. Cancer Epidemiol Biomarkers Prev 1995;4:807-811. [PubMed: 8634649]

30. Schnohr P, Gronbaek M, Petersen L, Hein HO, Sorensen TI. Physical activity in leisure-time and risk of cancer: 14-year follow-up of 28,000 Danish men and women. Scand J Public Health 2005;33:244249. [PubMed: 16087486]

31. Johnsen NF, Christensen J, Thomsen BL, et al. Physical activity and risk of colon cancer in a cohort of Danish middle-aged men and women. Eur J Epidemiol 2006;21:877-884. [PubMed: 17160429]

32. Calton BA, Lacey JV, Schatzkin A, et al. Physical activity and the risk of colon cancer among women: a prospective cohort study (United States). Int J Cancer 2006;119:385-391. [PubMed: 16489545]

33. Lee KJ, Inoue M, Otani T, Iwasaki M, Sasazuki S, Tsugane S. Physical activity and risk of colorectal cancer in Japanese men and women: the Japan Public Health Cancer-based prospective Study. Cancer Causes Control 2007;18:199-209. [PubMed: 17206529]

34. Mai PL, Sullivan-Halley J, Ursin G, et al. Physical activity and colon cancer risk among women in the California Teachers Study. Cancer Epidemiol Biomarkers Prev 2007;16:517-525. [PubMed: 17372247]

35. Wolin KY, Lee IM, Colditz GA, Glynn RJ, Fuchs C, Giovannucci E. Leisure-time physical activity patterns and risk of colon cancer in women. Int J Cancer 2007;121:2776-2781. [PubMed: 17722094]

36. Giovannucci E, Ascherio A, Rimm EB, Colditz GA, Stampfer MJ, Willett WC. Physical activity, obesity, and risk for colon cancer and adenoma in men. Ann Intern Med 1995;122:327-334. [PubMed: 7847643]

37. Colbert LH, Hartman TJ, Malila N, et al. Physical activity in relation to cancer of the colon and rectum in a cohort of male smokers. Cancer Epidemiol Biomarkers Prev 2001;10:265-268. [PubMed: 11303597]

38. Marcus PM, Newcomb PA, Storer BE. Early adulthood physical activity and colon cancer risk among Wisconsin women. Cancer Epidemiol Biomarkers Prev 1994;3:641-644. [PubMed: 7881336]

39. Schatzkin A, Subar AF, Thompson FE, et al. Design and serendipity in establishing a large cohort with wide dietary intake distributions: the National Institutes of Health-American Association of Retired Persons Diet and Health Study. Am J Epidemiol 2001;154:371-374.

40. Ainsworth BE, Haskell WL, Leon AS, et al. Compendium of physical activities: classification of energy costs of human physical activities. Med Sci Sports Exerc 1993;25:71-80. [PubMed: 8292105]

41. Pereira MA, FitzerGerald SJ, Gregg EW, et al. A collection of physical activity questionnaires for health-related research. Med Sci Sports Exerc 1997;29(6 Suppl):S1-205. [PubMed: 9243481]

42. Michaud DS, Midthune D, Hermansen S, et al. Comparison of cancer registry case ascertainment with SEER estimates and self-reporting in a subset of the NIH-AARP Diet and Health Study. J Regist Manag 2005;32:70-75.

43. Rich-Edwards JW, Corsano KA, Stampfer MJ. Test of the National Death Index and Equifax Nationwide Death Search. Am J Epidemiol 1994;140:1016-1019. [PubMed: 7985649]

44. Korn EL, Graubard BI, Midthune D. Time-to-event analysis of longitudinal follow-up of a survey: choice of the time-scale. Am J Epidemiol 1997;145:72-80. [PubMed: 8982025]

45. Ainsworth BE, Irwin ML, Addy CL, Whitt MC, Stolarczyk LM. Moderate physical acitivity patterns of minority women: The Cross-Cultural Activity Participation Study. J Womens Health Gend Based Med 1999;8:805-813. [PubMed: 10495261]

46. Schor, JB. The overworked American. Harper Collins; New York: 1992.

47. Ainsworth BE. Challenges in measuring physical activity in women. Exerc Sport Sci Rev 2000;28:9396. [PubMed: 10902093]

48. Gerhardsson de Verdier M, Norell SE, Kiviranta H, Pedersen NL, Ahlbom A. Sedentary jobs and colon cancer. Am J Epidemiol 1986;123:775-780. [PubMed: 3962961]

49. Severson RK, Nomura AM, Grove JS, Stemmermann GN. A prospective analysis of physical activity and cancer. Am J Epidemiol 1989;130:522-529. [PubMed: 2763997] 
50. Iacopetta B. Are there two sides to colorectal cancer? Int J Cancer 2002;101:403-408. [PubMed: 12216066]

51. Isomura K, Kono S, Moore MA, et al. Physical activity and colorectal cancer: the Fukuoka Colorectal Cancer Study. Cancer Sci 2006;97:1099-1104. [PubMed: 16918995]

52. Slattery ML, Edwards S, Curtin K, et al. Physical activity and colorectal cancer. Am J Epidemiol 2003;158:214-224. [PubMed: 12882943]

53. Le Marchand L, Wilkens LR, Kolonel LN, Hankin JH, Lyu LC. Associations of sedentary lifestyle, obesity, smoking, alcohol use, and diabetes with the risk of colorectal cancer. Cancer Res 1997;57:4787-4794. [PubMed: 9354440]

54. Slattery ML, David R, Jacobs J. Assessment of ability to recall physical activity of several years ago. Ann Epidemiol 1995;5:292-296. [PubMed: 8520711]

55. Wei EK, Giovannucci E, Wu K, et al. Comparison of risk factors for colon and rectal cancer. Int J Cancer 2004;108:433-442. [PubMed: 14648711] 


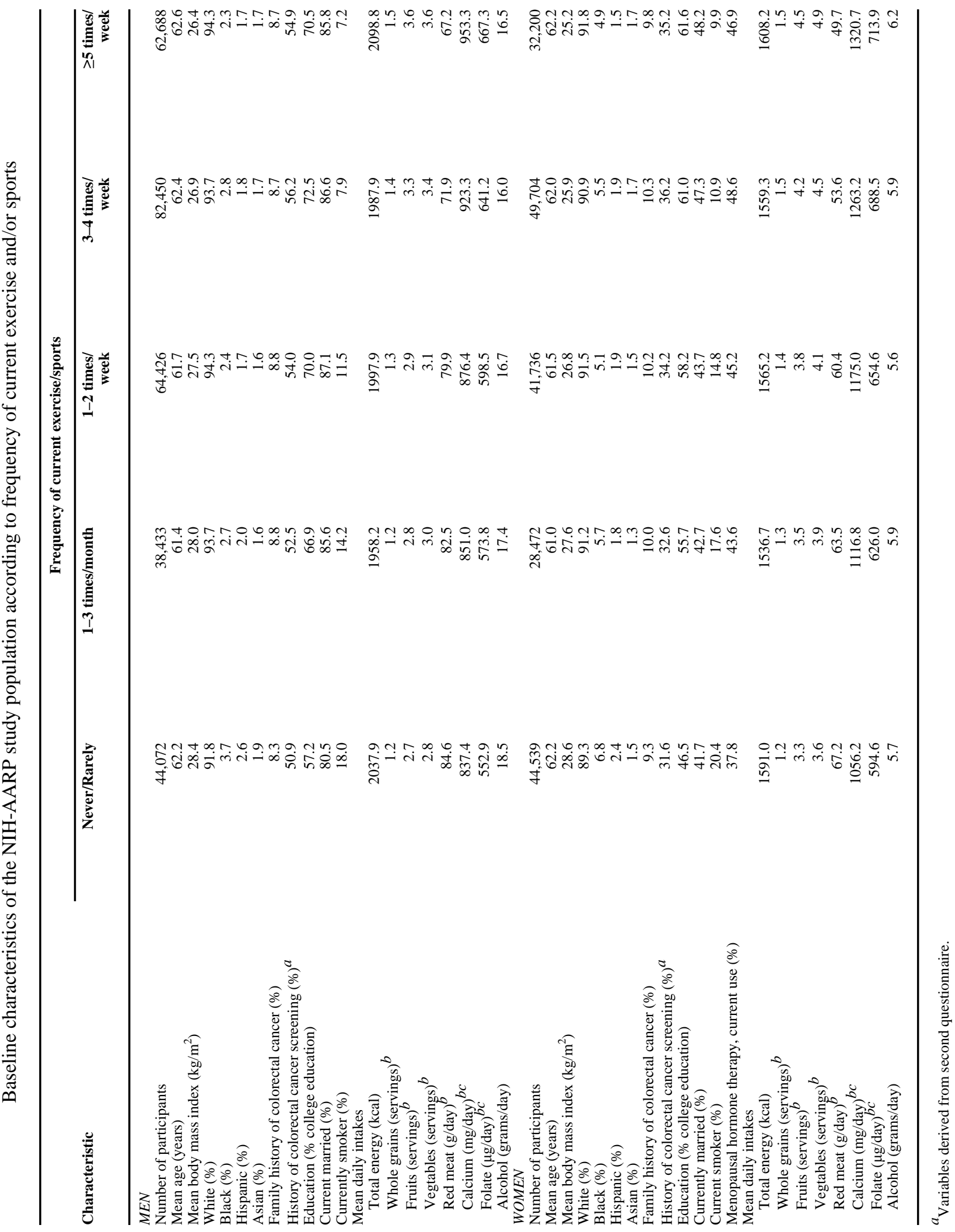

Cancer Causes Control. Author manuscript; available in PMC 2009 November 1. 


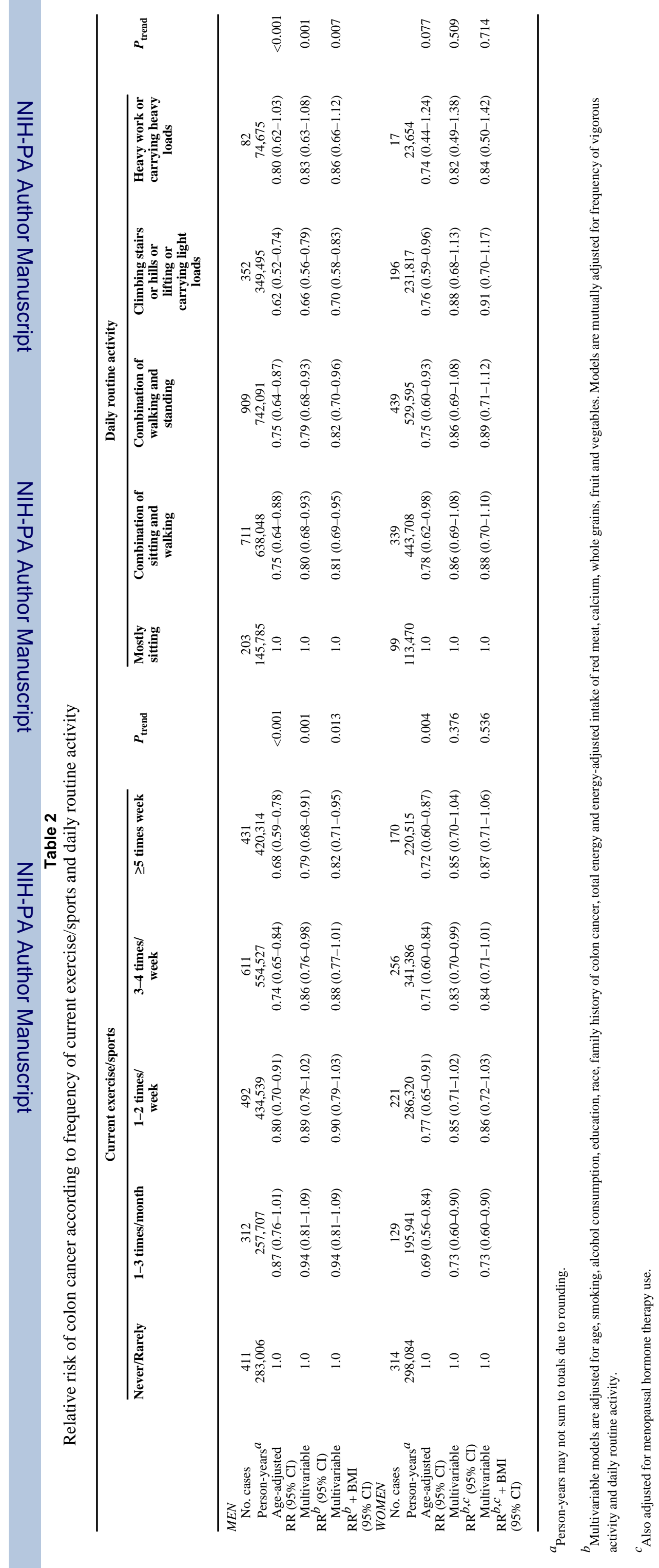




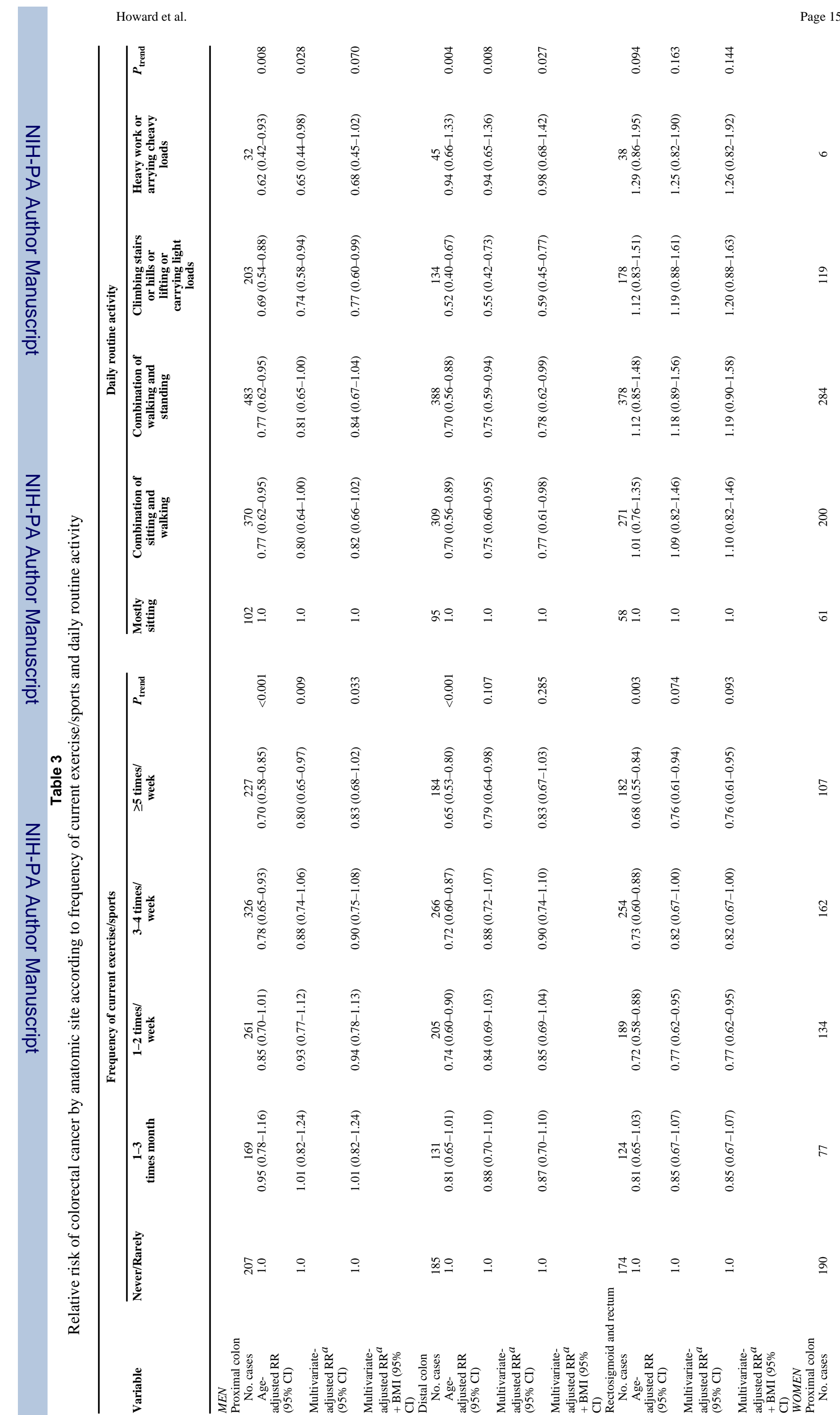




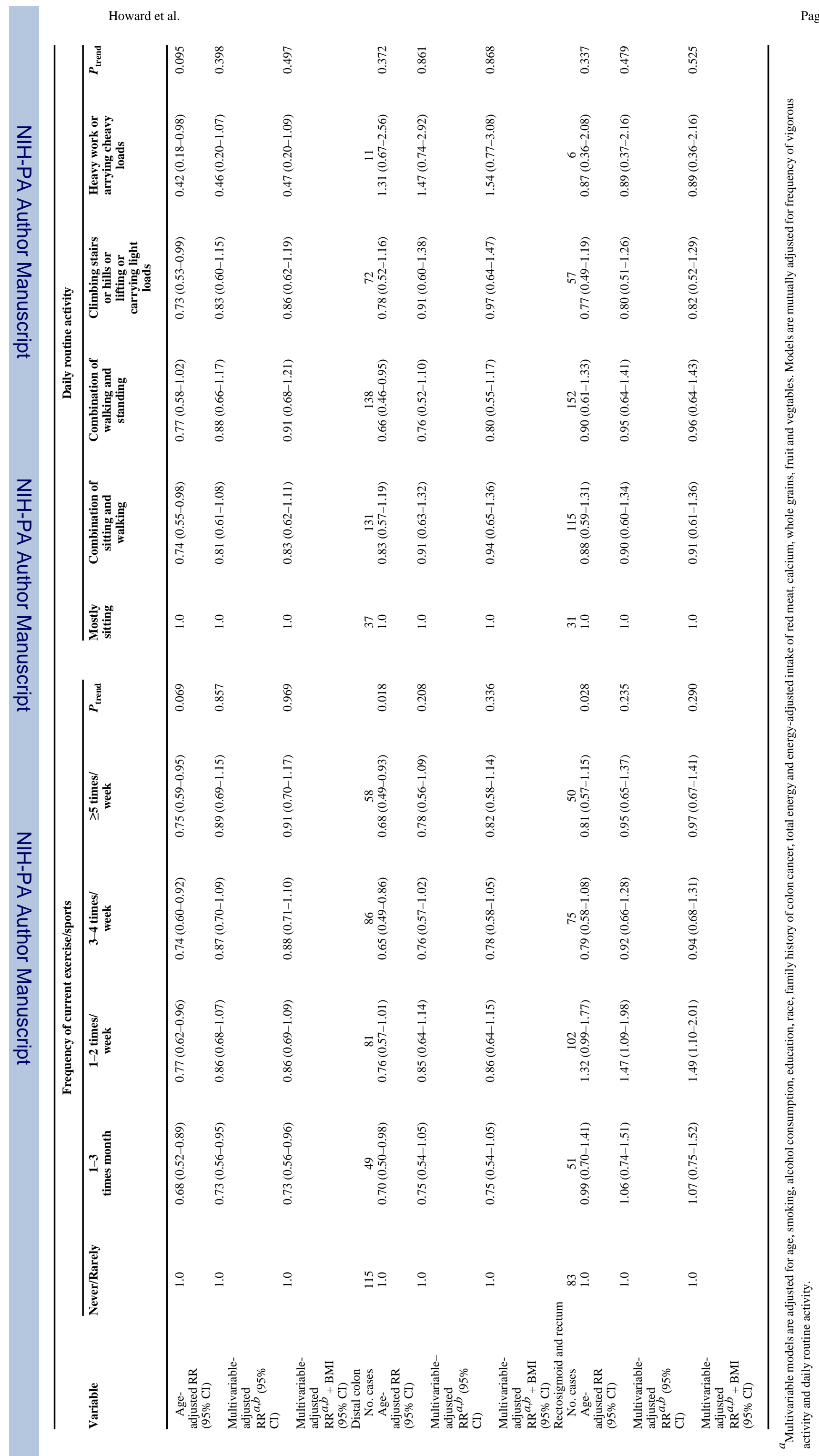

Page 16 


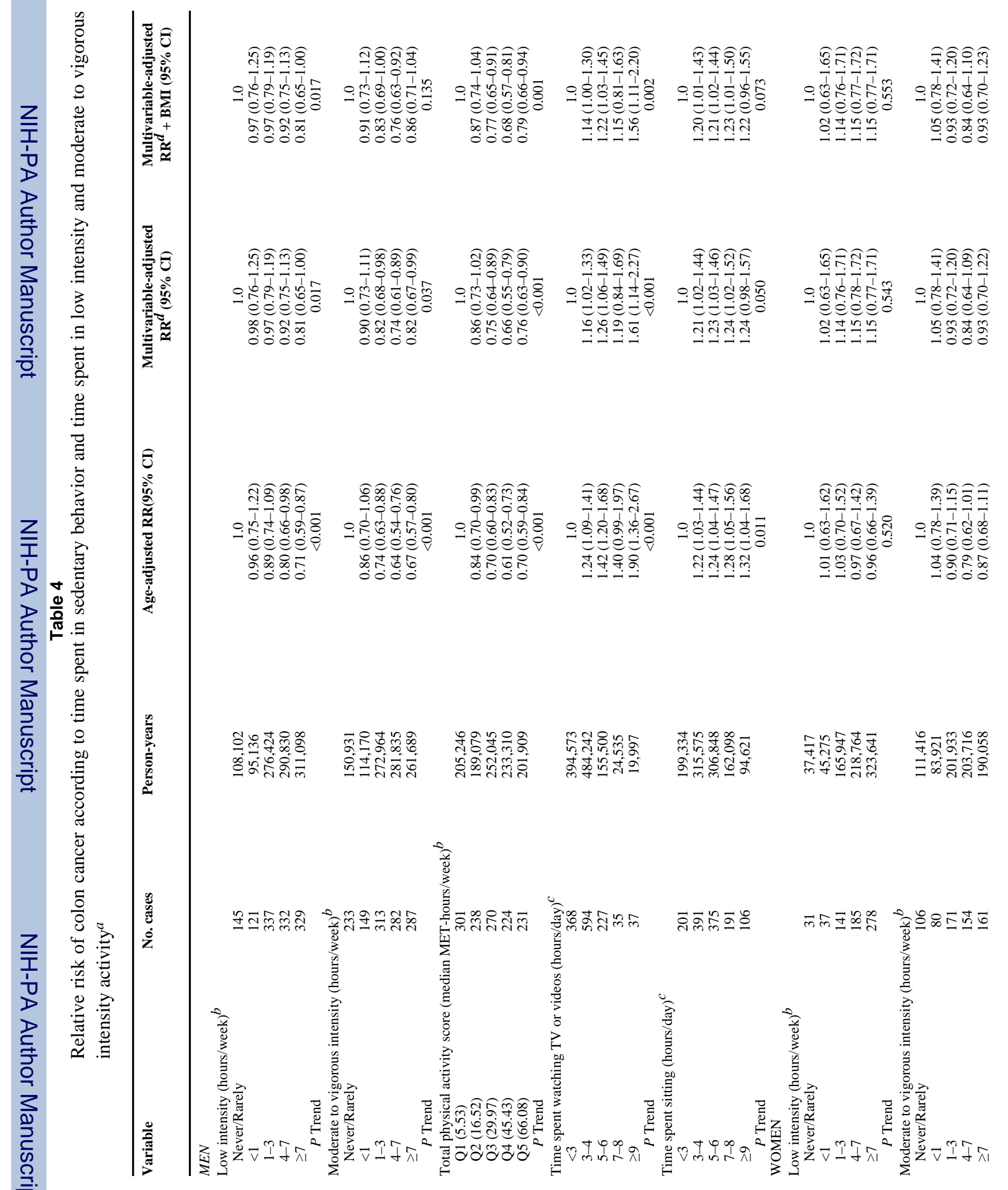


Howard et al.

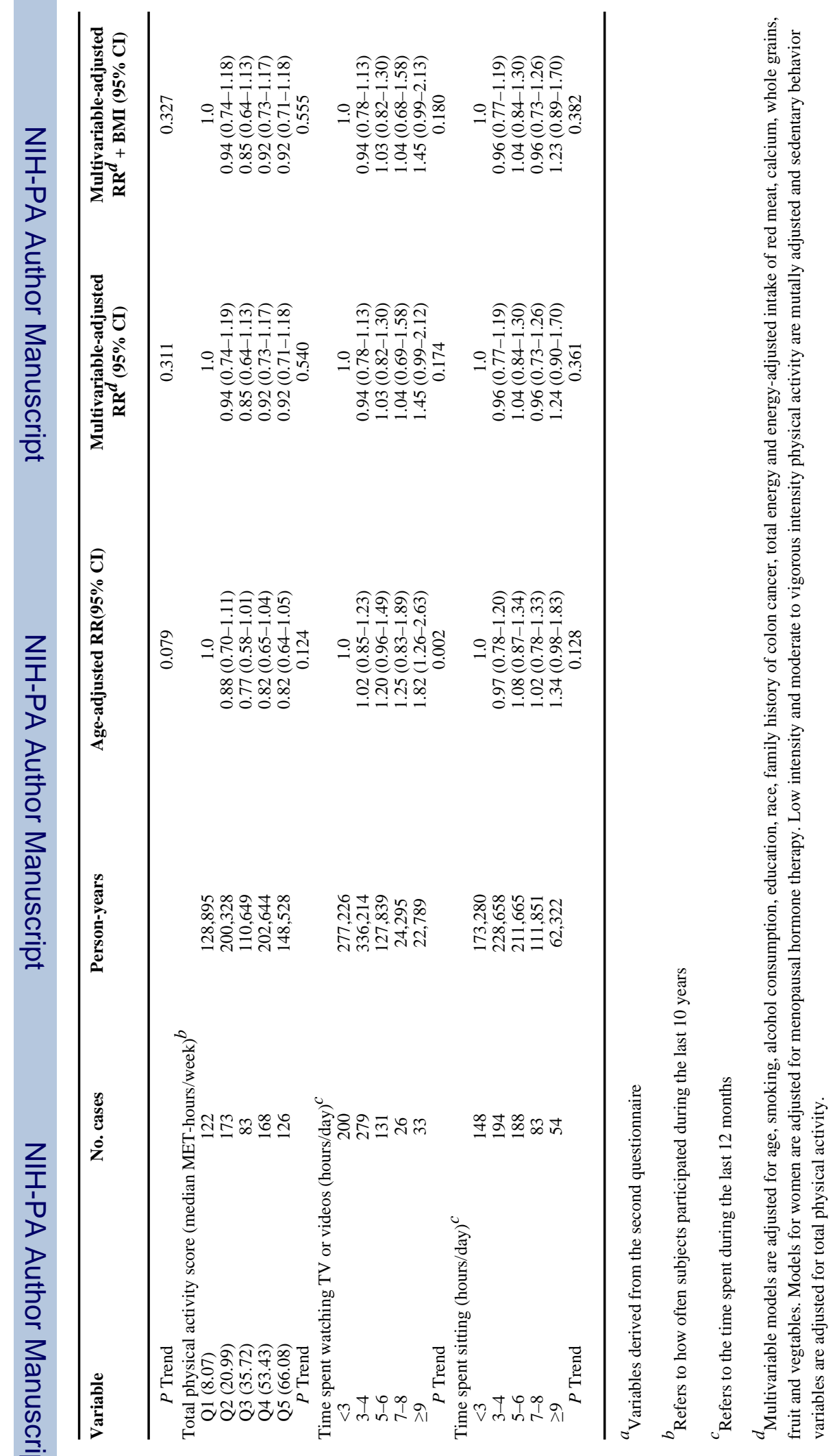

Cancer Causes Control. Author manuscript; available in PMC 2009 November 1. 


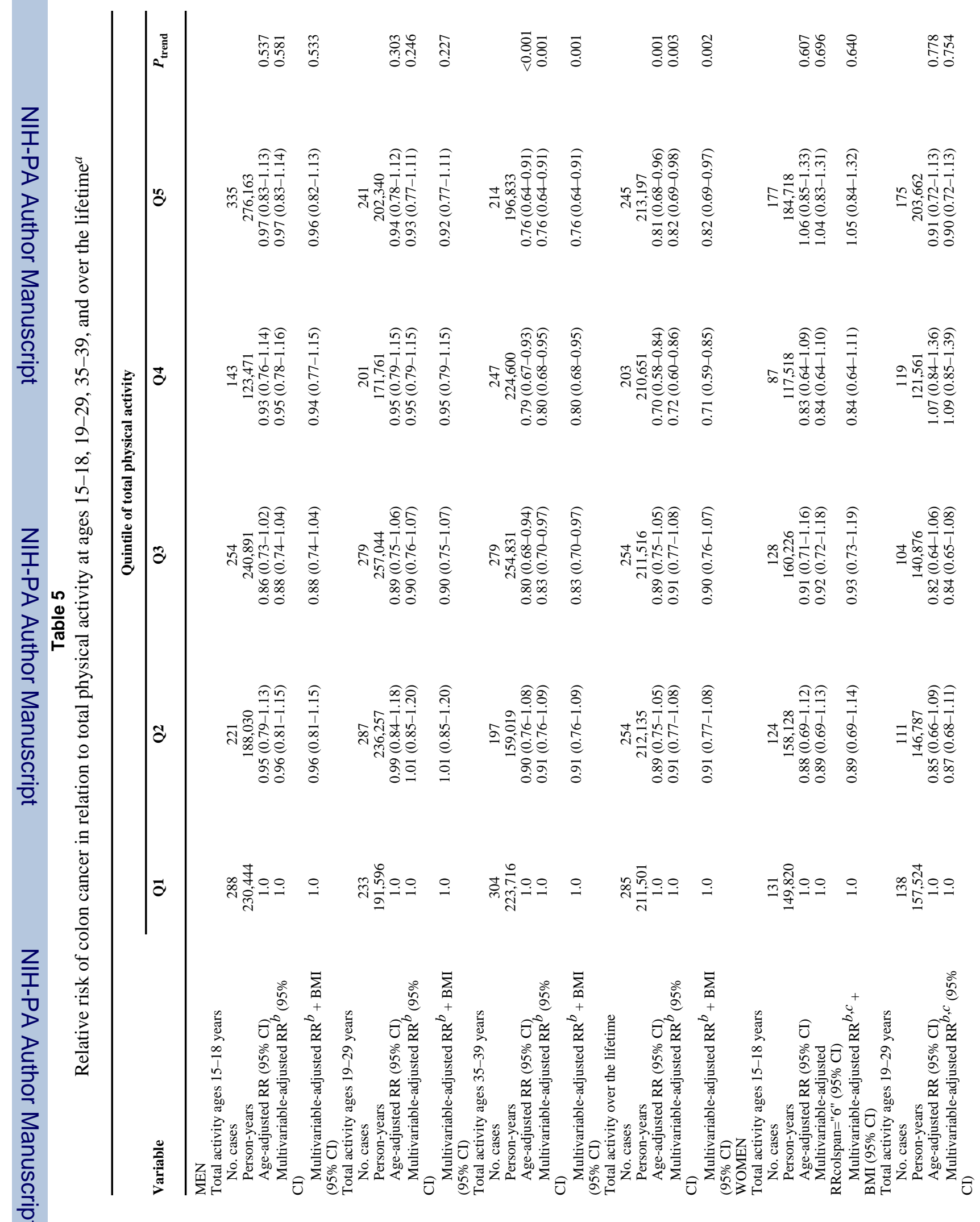

Cancer Causes Control. Author manuscript; available in PMC 2009 November 1. 
Howard et al.

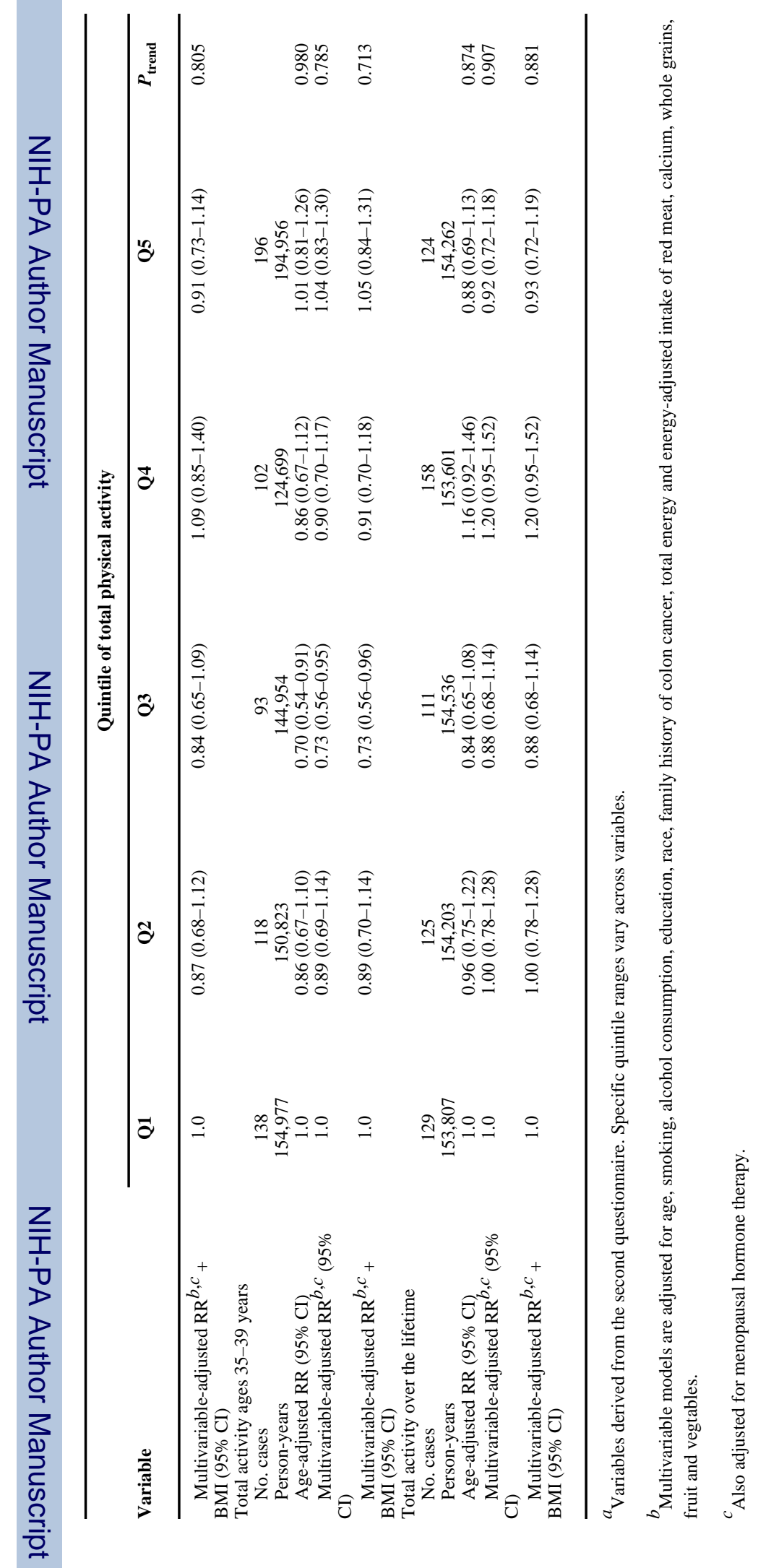

